\title{
Analisis Dampak dan Strategi untuk Meningkatkan Akses Pasar Indonesia dalam Menghadapi Indonesia EFTA Comprehensive Economic Partnership Agreement (IE CEPA)
}

\author{
Deky Paryadia,* \\ ${ }^{a}$ Badan Pengkajian dan Pengembangan Perdagangan, Kementerian Perdagangan
}

\begin{abstract}
This analysis was conducted to determine the impact and strategy of Indonesia in facing the ratification of Indonesia EFTA CEPA (IE CEPA) trade cooperation. This method uses the GTAP Model to see the impact that will be obtained and also uses the SWOT method to obtain the best strategy for Indonesia. The results of Cost Benefit IE CEPA simulation show correlated results between increases in output in several sectors (meat products, apparels and textiles) followed by an increase in the trade balance in similar sectors. The strategy that must be set in this position is an aggressive growth policy (Growth-oriented Strategy). This offensive position can be considered by looking at the results of the Cost Benefit to increase Indonesia's output for sectoral production which will also affect employment in Indonesia.
\end{abstract}

Keywords: IE-CEPA; SWOT; cost benefit

\begin{abstract}
Abstrak
Analisis ini dilakukan untuk mengetahui dampak dan strategi Indonesia dalam menghadapi ratifikasi kerja sama perdagangan Indonesia EFTA CEPA (IE CEPA). Metode ini menggunakan GTAP Model untuk melihat dampak yang akan diperoleh dan juga menggunakan metode SWOT untuk memperoleh strategi terbaik bagi Indonesia. Hasil simulasi Cost Benefit IE CEPA menunjukkan hasil yang berkorelasi antara kenaikan output di beberapa sektor (meat product, apparel, dan textiles) yang diikuti dengan adanya peningkatan neraca perdagangan di sektor yang sejenis. Strategi yang harus ditetapkan pada posisi ini adalah kebijakan pertumbuhan yang agresif (Growth-oriented Strategy). Posisi offensive ini dapat dipertimbangkan dengan melihat hasil cost benefit terhadap peningkatan output Indonesia bagi produksi sektoral yang juga akan berpengaruh terhadap penyerapan tenaga kerja di Indonesia.
\end{abstract}

Kata Kunci: IE-CEPA; SWOT; cost benefit

Kode Klasifikasi JEL: F13; F15; F17

${ }^{*}$ Alamat Korespondensi Penulis: Pusdiklat Kementerian Perdagangan, Jln. Abdul Wahab No. 38, Kedaung, Kec. Sawangan, Kota Depok, Jawa Barat 16516. E-mail: deckyparyadi@gmail.com. 


\section{Pendahuluan}

European Free Trade Association (EFTA) adalah organisasi antar-pemerintahan yang didirikan untuk mendorong perdagangan bebas dan integrasi ekonomi untuk kepentingan negara-negara anggotanya (Islandia, Liechtenstein, Norwegia, dan Swiss) serta negara mitranya. EFTA yang didirikan pada 3 Mei 1960, yang merupakan asosiasi perdagangan bebas beranggotakan empat negara, yaitu Swiss, Liechtenstein, Islandia, dan Norwegia. Pada 1 Januari 2003, pintu gerbang akses pasar produk EFTA ke Asia dibuka: EFTA-Singapura mulai berlaku. EFTA telah menyelesaikan perjanjian perdagangan preferensial pertamanya dengan mitra Asia. Perjanjian tersebut adalah salah satu dari sebagian besar perjanjian komprehensif yang pernah dilakukan oleh EFTA (Rao, 2011). Pada tahun 2019, ekspor CPO dan produk turunannya dari Indonesia secara keseluruhan sebesar 28,3 juta ton, meningkat 1,3\% dari 27,9 juta ton pada 2018. Negara tujuan utama ekspor produk CPO Indonesia adalah Cina, Uni Eropa, India, Afrika, dan Pakistan dengan kontribusi sebesar $62 \%$ terhadap total ekspor Indonesia ke dunia (Trade Map, 2019).

Perundingan Persetujuan Kemitraan Ekonomi Komprehensif dengan Indonesia (Indonesia-EFTA Comprehensive Economic Partnership Agreement, IE-CEPA) dimulai secara resmi pada tahun 2007. Perundingan ini merupakan bagian penting dari strategi EFTA di Asia Tenggara. Melalui Perjanjian Kemitraan Ekonomi Komprehensif (Indonesia-EFTA Comprehensive Economic Partnership Agreement/IE-CEPA) akan memungkinkan peningkatan dan diversifikasi perdagangan dan investasi dua arah. Peningkatan perdagangan dan investasi akan membuka kesempatan baru bagi dunia usaha, tenaga kerja, serta konsumen yang akan berdampak pada peningkatan kesejahteraan di Indonesia dan negara-negara EFTA.

Pada 16 Desember 2018, kerja sama komprehensif Indonesia dan EFTA (IECEPA) ditandatangani di Jakarta. Dalam perjanjian ini disetujui bahwa kerja sama ini akan diratifikasi dalam waktu 90 hari sejak ditanda-tanganinya perjanjian. Menurut UU No. 7 tahun 2014 tentang Perdagangan semua perjanjian perdagangan internasional yang ditandatangani pemerintah harus dibahas dengan Dewan Perwakilan Rakyat (DPR) dan untuk memutuskan apakah perjanjian perdagangan internasional tersebut ditandatangani atau tidak memerlukan persetujuan dari DPR. Perjanjian perdagangan internasional perlu persetujuan DPR apabila DPR berpendapat perjanjian tersebut menimbulkan akibat yang luas dan mendasar bagi kehidupan rakyat yang terkait dengan beban keuangan negara; dan/atau perjanjian tersebut mengharuskan perubahan undang-undang. Dalam hal perjanjian tersebut tidak menimbulkan dampak besar bagi keuangan negara, maka pengesahan perjanjian tersebut dapat dilakukan dengan Peraturan Presiden dan perundang-undangan yang lebih rendah.

Adanya kerja sama perdagangan bebas diharapkan akan mengurangi hambatan perdagangan sehingga akan mendorong adanya investasi yang dapat memacu pertumbuhan volume perdagangan internasional. Selain itu, pengurangan hambatan perdagangan akan dapat memberikan dampak positif terhadap ekonomi 
suatu negara (Itakura, 2014). Efek langsungnya adalah peningkatan kegiatan ekonomi yang diperoleh dari penghapusan hambatan perdagangan (Stevens et al., 2015). Salah satu upaya yang dilakukan adalah kerja sama yang dilakukan antara satu negara dengan negara lainnya atau antara satu negara dengan negara yang membentuk kelompok sehingga terciptanya integrasi ekonomi. Integrasi ekonomi di suatu kawasan memiliki beberapa manfaat untuk negara-negara yang tergabung dalam integrasi tersebut, seperti terdorongnya efisiensi ekonomi di suatu kawasan ekonomi, mendorong industri lokal agar berkembang, serta manfaat perdagangan yang meningkat akibat adanya perbaikan terms of trade (Meier, 1995).

Suatu organisasi terdiri dari berbagai bentuk, tergantung tingkat kerja samanya yang mengarah ke tingkat integrasi berbeda antara negara peserta. Ada lima tingkat kerja sama formal antara negara anggota kelompok regional, yaitu Free Trade Area (FTA), Custom Union, Common Market, Monetary Union, dan Political Union (Kotabe \& Helsen, 2001). Free Trade Area (FTA) adalah kerja sama formal antara dua atau lebih negara untuk mengurangi hambatan tarif dan non-tarif di antara negara anggota. Akan tetapi, masing-masing negara anggota bebas menentukan tingkat tarif individu dengan negara yang bukan anggota.

Integrasi ditujukan untuk memaksimalkan potensi ekonomi, memaksimalkan potensi politik, meningkatkan solidaritas entitas, serta mengurangi dan menyelesaikan potensi konflik menuju satu kesatuan. Integrasi internasional tidak berjalan secara cepat melainkan perlahan melalui proses panjang yang tersusun, artinya proses itu bermula dari beberapa sektor kemudian berkembang dan makin meningkat menjadi satu kesatuan (Salamah, 2017).

Dari teori dan studi literatur yang penulis lakukan, dalam kajian ini penulis akan melihat dampak kerja sama perdagangan Indonesia dan EFTA CEPA (IE FTA). Walaupun kerja sama Indonesia EFTA dalam skema Comprehensive Economic Partneship Agreement (CEPA), namun ruang lingkup analisis kajian ini adalah hanya lingkup perdagangan barang.

Adapun kajian analisis ini akan melihat cost benefit serta strategi apa yang dapat diambil oleh pemerintah Indonesia terkait kerja sama Indonesia - EFTA CEPA (IE CEPA). Adapun tujuan dari kajian ini adalah sebagai berikut: (1) mengetahui dampak biaya dan manfaat terhadap isi perjanjian IE-CEPA, dan (2) mengetahui strategi terbaik bagi Indonesia dalam perjanjian IE-CEPA.

\section{Metodologi}

Analisis ini menggunakan metode Cost-benefit Analysis yang akan menggunakan pendekatan kuantitatif serta analisis SWOT dengan memasukkan data sekunder dan primer kemudian dianalisis dengan pendekatan kualitatif. Data primer untuk analisis SWOT diperoleh melalui Focus Group Discussion (FGD), sedangkan data sekunder lainnya diperoleh melalui data perdagangan Indonesia dan EFTA, baik secara bilateral maupun kinerja perdagangan dengan dunia. Analisis ini menggunakan indikator perdagangan di antaranya neraca perdagangan 
bilateral dan global, produk ekspor dan impor utama, serta indeks daya saing Revealed Comparative Advantage. Analisis ini menghitung dampak (manfaat dan biaya) kerja sama perdagangan dengan menggunakan analisis Computable General Equilibrium (CGE).

\subsection{Cost-benefit Analysis}

Untuk mengetahui dampak (cost \& benefit) dari sebuah kerja sama perdagangan antar kedua negara dapat digunakan model Computable General Equilibrium (CGE) yang dengan data dasar GTAP versi 9 dengan data sekunder utama yang diterbitkan tahun 2015. GTAP versi 9 terdapat pembaharuan dalam hal data yang menggunakan data referensi tahun 2004, 2007, dan 2011 dan terdiri dari 140 region dan 57 sektor. Hasil dari perkiraan dampak kerja sama dapat digunakan untuk menilai potensi dari suatu kerja sama perdagangan. Selain itu, data sekunder yang lain diperoleh melalui data Badan Pusat Statistik (data ekspor impor Indonesia dengan negara anggota EFTA) dan Trademap (untuk mengetahui ekspor impor 6 digit dari dunia).

Selain itu, untuk melihat potensial produk yang memilik daya saing, digunakan perhitungan Revealed Comparative Advantage (RCA) yang dikembangkan oleh Balassa (1965). RCA ini adalah salah satu tools untuk melihat daya saing secara relatif suatu produk. Indeks RCA Balassa pada dasarnya mengukur pangsa (share) ekspor suatu negara yang dinormalkan dengan ekspor pada industri atau produk yang sama dalam satu kelompok negara (Anggoro \& Widyastutik, 2016). Formula RCA Balassa dimodifikasi sedemikian sehingga indeks tersebut simetris pada batas nilai satu dengan menggunakan formula berikut ini:

$$
R S C A=\frac{R C A-1}{R C A+1}
$$

Dengan formula tersebut, nilai indeks RCA yang lebih dari satu akan memiliki indeks RSCA bernilai positif, sedangkan RCA yang bernilai kurang dari satu akan memiliki indeks RSCA negatif. Hasil dari RSCA yang memiliki daya saing bagus ini kemudian dilihat menggunakan tools CGE sehingga dapat memilih sektor-sektor yang berdaya saing yang dapat dilihat dampaknya dalam kerja sama IE CEPA ini.

\subsection{SWOT Analysis}

Untuk menyusun strategi melaksanakan perjanjian IE-CEPA dilakukan analisa SWOT. Analisa SWOT adalah peralatan analisa yang digunakan untuk menyusun strategi dengan memperhatikan lingkungan internal dan eksternal suatu perekonomian. Dalam kaitan dengan pelaksanaan perjanjian perdagangan IECEPA, analisa SWOT digunakan untuk mengetahui apakah faktor-faktor internal Indonesia memberikannya posisi yang kuat dalam melaksanakan perjanjian ini, atau apakah faktor-faktor internal tersebut menempatkan Indonesia di posisi 
yang lemah. Pada saat yang sama, analisa SWOT akan membantu mengetahui apakah dengan kondisi ekternal yang ada melaksanakan perjanjian ini akan menciptakan kesempatan baru bagi Indonesia, ataukah dengan kondisi ekternal yang ada melaksanakan perjanjian ini akan menimbulkan ancaman bagi Indonesia.

Hasil analisa SWOT ini akan menunjukkan apakah dengan kondisi lingkungan internal dan eksternal ini meratifikasi perjanjian ini merupakan strategi yang tepat bagi Indonesia. Apabila kondisi lingkungan tidak menguntungkan bagi Indonesia, strategi apa yang harus dilakukan Indonesia untuk dapat memanfaatkan perjanjian ini secara optimal karena analisa kuantitatif menunjukkan bahwa ada manfaat positif dari perdagangan dengan EFTA.

\section{Hasil dan Pembahasan}

\subsection{Perdagangan Indonesia dengan EFTA}

Data Badan Pusat Statistik menunjukkan, EFTA merupakan negara tujuan ekspor ke-32 dan negara asal impor ke-27 terbesar bagi Indonesia. Pada tahun 2018, total perdagangan Indonesia-EFTA mencapai USD1,7 miliar. Nilai ekspor Indonesia ke EFTA sebesar USD732,8 miliar dan impor Indonesia dari EFTA sebesar USD1,06 miliar. Indonesia mengalami defisit perdagangan dengan EFTA sebesar USD331,9 juta.

Ekspor utama Indonesia ke EFTA pada tahun 2018, antara lain: (1) perhiasan (USD525 juta); (2) lensa kontak (USD65,2 juta); (3) emas batangan (USD22,7 juta); (4) monitor dan proyektor televisi (USD9,2 juta); dan (5) essential oil (USD5,3 juta). Adapun ekspor utama Indonesia ke masing-masing negara EFTA, antara lain adalah ke Swiss (perhiasan, lensa kontak, emas batangan, essential oil, bahan pewarna sintetik), Norwegia (monitor televisi, pipa besi, arang kayu, nanas, tisu toilet linen), Islandia (monitor televisi, ban karet, kayu manis, furnitur, jus nanas), Liechtenstein (mesin makanan, pakaian wanita, furnitur, peralatan survei) (BPS, 2019a).

Sedangkan untuk impor utama Indonesia dari EFTA, antara lain: (1) emas batangan (USD203,7 juta); (2) minyak petroleum mentah (USD41,5 juta); (3) turbin hidrolik (USD35,5 juta); (4) minyak petroleum (USD34,3 juta); dan (5) alumunium (USD33,7 juta). Adapun impor utama Indonesia ke masing-masing negara EFTA, antara lain adalah ke Swiss (emas batangan, bagian gas turbin, alumunium, tinta printer, obat vitamin A), Norwegia (minyak petroleum, bensin RON, ikan trout, salmon atlantik, pupuk), Islandia (ikan makarel, telur ikan beku, alumunium foil, selulosa kimia), Liechtenstein (perlengkapan pancing, peralatan listrik, lampu infrared, kabel konektor) (BPS, 2019b).

\subsection{Dampak Liberalisasi Perdagangan Indonesia-EFTA}

Penurunan hambatan perdagangan di dalam perjanjian IE-CEPA memiliki dampak ekonomi yang bisa dikuantifikasi dengan menggunakan simulasi Computable 
General Equilibrium. Studi ini melakukan perhitungan simulasi eliminasi penurunan tarif terhadap produk (pos tarif) kedua negara hingga $0 \%$. Hasil simulasi CGE ini berfokus kepada dampak IE-CEPA terhadap ekspor, impor, output produksi, dan GDP. Hasil simulasi ini dapat dilihat dari gambar-gambar berikut.

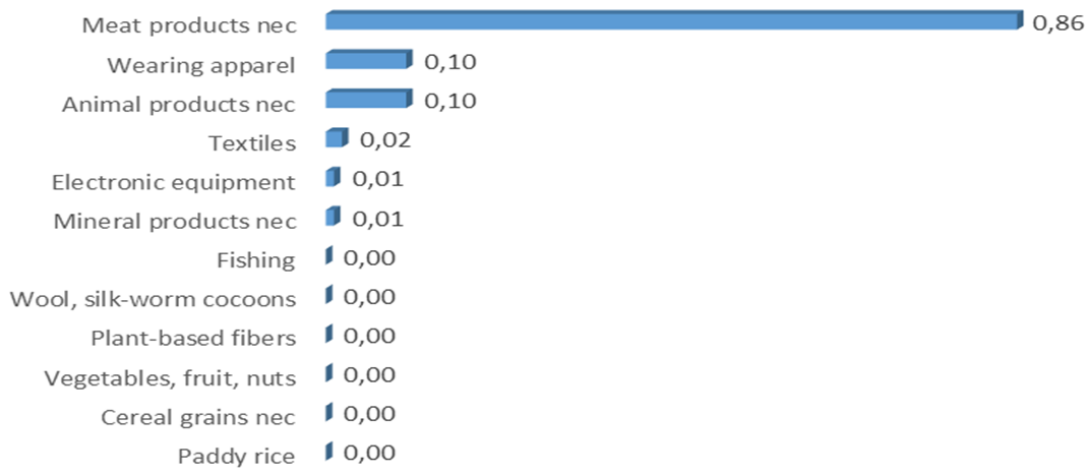

Gambar 1: Output Sektoral Indonesia (USD Juta)

Sumber: Hasil simulasi CGE

Dampak skema kerja sama perdagangan Indonesia dan EFTA terhadap ekonomi sektoral dilihat dari indikator-indikator persentase perubahan output, ekspor, dan impor sektoral. Dampak penghapusan tarif menjadikan peningkatan output di Indonesia untuk beberapa sektor, antara lain meat products, apparel, animal products, textiles, electronic equipment, dan mineral products.

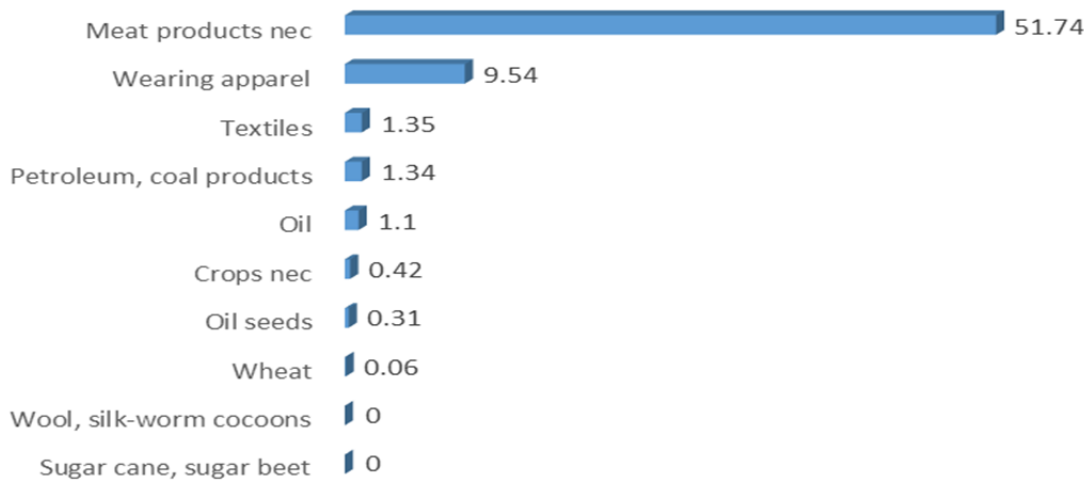

Gambar 2: Neraca Perdagangan Sektoral Indonesia (USD Juta) Sumber: Hasil simulasi CGE

Pada Gambar 2 terlihat sektor yang mengalami peningkatan output pada Gambar 1, neraca perdagangannya terlihat mengalami surplus, seperti yang ter- 
jadi pada sektor meat products, wearing appareal, dan textiles. Kenaikan output dari beberapa sektor tersebut menyebabkan excess supply sehingga akan mendorong peningkatan ekspor Indonesia yang kemudian akan juga menyebabkan surplus neraca perdagangan bagi Indonesia.

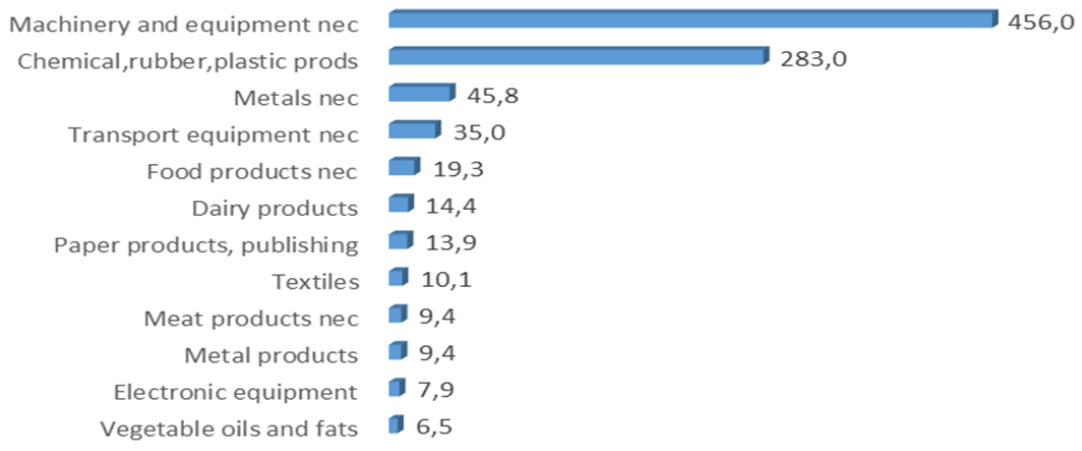

Gambar 3: Ekspor Sektoral Indonesia ke Swiss (USD Juta)

Sumber: Hasil simulasi CGE

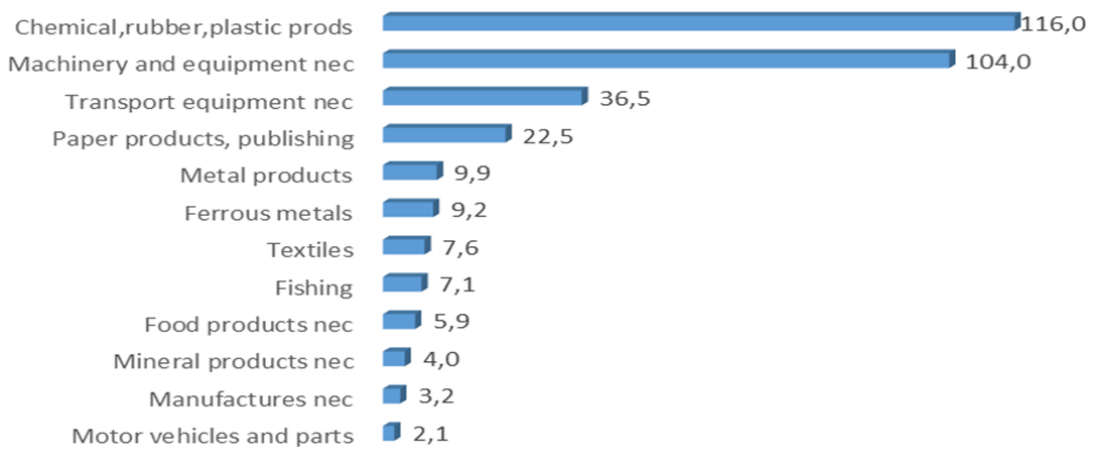

Gambar 4: Ekspor Sektoral Indonesia ke Norwegia (USD Juta) Sumber: Hasil simulasi CGE

Dari hasil simulasi CGE (Gambar 3-5), apabila disimulasikan penurunan tarif hingga 100\% dalam skema kerja sama Indonesia - EFTA, maka akan terjadi dampak kenaikan ekspor bagi sektor Indonesia ke masing-masing negara EFTA. Beberapa sektor yang akan mengalami kenaikan ekspor terbesar bagi Indonesia ke negara-negara EFTA relatif sama untuk masing-masing negara, yaitu antara lain sektor mesin, kimia/karet, logam, alat transportasi, dan produk makanan. 


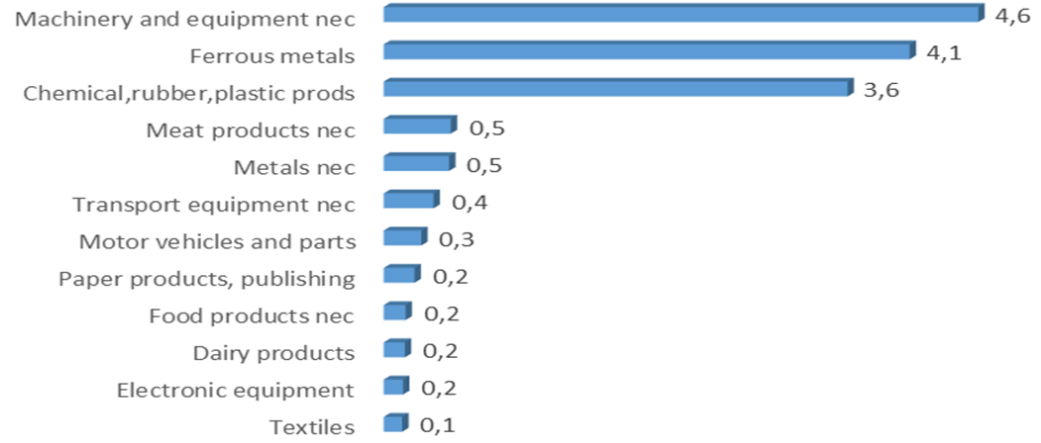

Gambar 5: Ekspor Sektoral Indonesia ke Islandia/Liechtenstein (USD Juta) Sumber: Hasil simulasi CGE

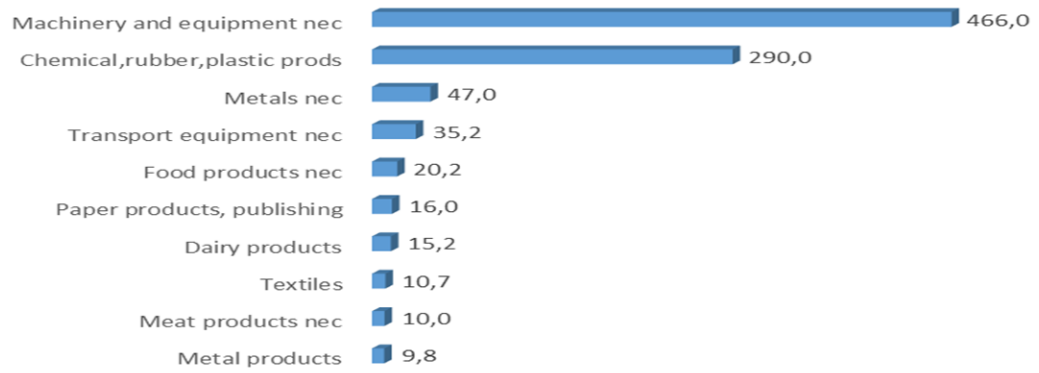

Gambar 6: Impor Sektoral Indonesia dari Swiss (USD Juta)

Sumber: Hasil simulasi CGE

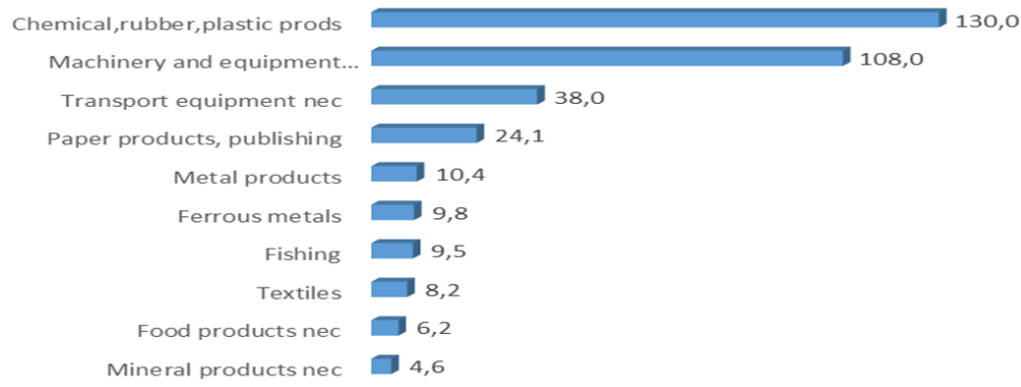

Gambar 7: Impor Sektoral Indonesia dari Norwegia (USD Juta)

Sumber: Hasil simulasi CGE 


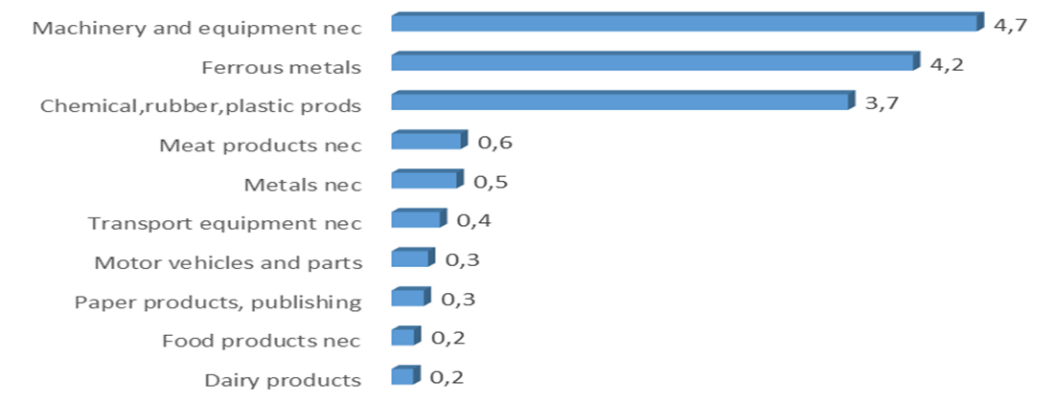

Gambar 8: Impor Sektoral Indonesia dari Islandia/Liechtenstein (USD Juta) Sumber: Hasil simulasi CGE

Dari hasil simulasi CGE (Gambar 6-7), yaitu dengan simulasi penurunan tarif hingga $100 \%$ beberapa sektor mengalami dampak kenaikan impor dari negara EFTA. Sektor yang mengalami kenaikan impor dari Swiss antara lain: sektor mesin, kimia/karet, logam, alat transportasi, dan produk makanan. Sementara kenaikan impor terbesar dari Norwegia akan terjadi pada sektor kimia/karet, mesin, alat transportasi, kertas, dan logam. Sedangkan kenaikan impor terbesar dari Islandia terjadi pada sektor mesin, logam, kimia/karet, produk daging, dan logam.

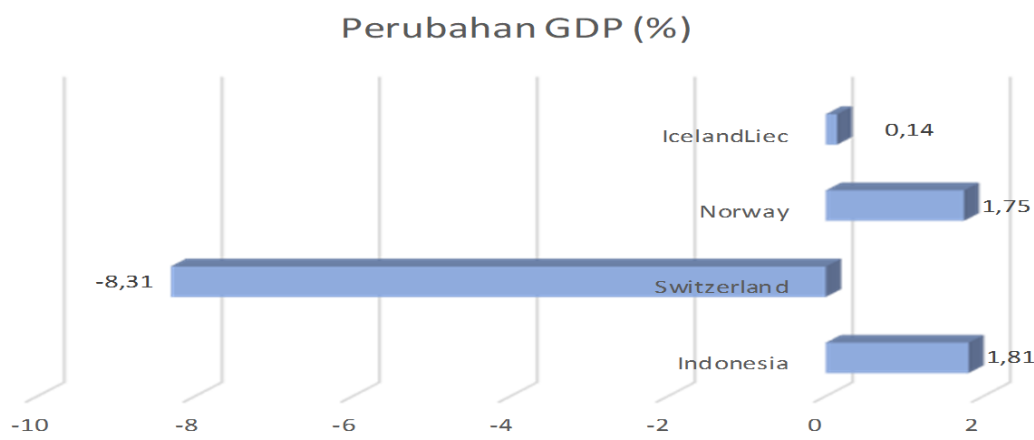

Gambar 9: Prediksi Perubahan GDP dengan setelah IE CEPA Sumber: Hasil simulasi CGE

Berdasarkan hasil simulasi CGE model yang dilakukan (Gambar 9), dengan penurunan tarif hingga 100\% dari total tarif Indonesia dan EFTA, menunjukkan adanya kerja sama IE-CEPA ini akan membuat Indonesia memperoleh peningkatan GDP sebesar 1,81\%. Kenaikan output pada beberapa sektor mampu mendongkrak peningkatan GDP riil Indonesia. Sementara itu GDP Swiss menurun sebesar $-8,31 \%$, namun demikian, Norwegia dan Islandia akan memperoleh peningkatan GDP sebesar $1,75 \%$ dan $0,14 \%$. 


\subsection{Analisa SWOT}

Pengumpulan data untuk analisa SWOT ini dilakukan melalui focus group discussion (FGD). Data yang dikumpulkan dalam FGD ini menyangkut 12 tema utama dalam perjanjian IE-CEPA. Dalam FGD SWOT ini, digunakan metode expertise sampling, dimana responden yang diundang merupakan orang-orang yang memang mewakili, menguasai, dan memahami permasalahan dalam perundingan IE CEPA. Responden tersebut berasal dari instansi pemerintah (Kementerian dan Lembaga), asosiasi pengusaha, akademisi, dan lembaga riset. Pada FGD diusulkan atau ditawarkan beberapa faktor internal yang menjadi kekuatan dan kelemahan serta faktor eksternal yang membuka kesempatan atau yang menimbulkan ancaman bagi Indonesia. Peserta FGD diminta untuk memberi komentar terhadap faktor-faktor yang diusulkan ini dan menyampaikan tambahan faktor-faktor lain yang dinilai penting.

Setelah faktor-faktor utama kekuatan, kelemahan untuk setiap tema dan faktor-faktor kesempatan dan ancaman teridentifikasi, faktor-faktor tersebut diberi bobot tingkat kepentingan. Dalam pembobotan ini apabila responden menganggap faktor-faktor kekuatan secara agregat lebih penting (kurang penting) dibandingkan faktor-faktor kelemahan, maka faktor-faktor kekuatan harus diberi bobot yang lebih tinggi (rendah) dibandingkan kelemahan. Untuk mencegah terjadinya terjadinya bias pembobotan karena ada kemungkinan faktor-faktor kekuatan secara keseluruhan lebih penting dari faktor-faktor kelemahan (atau sebaliknya), maka pembobotan dilakukan terhadap gabungan faktor-faktor kekuatan dan kelemahan. Pendekatan yang sama dilakukan untuk faktor-faktor kesempatan dan ancaman.

Setelah dilakukan pembobotan proses berikutnya adalah memberikan score terhadap faktor-faktor tersebut. Jarak score tersebut adalah antara nilai 1 sampai dengan 5, dimana nilai terendah (1) menunjukkan bahwa faktor tersebut merupakan kelemahan bagi Indonesia, sedangkan nilai tertinggi (5) menunjukkan bahwa faktor tersebut merupakan kekuatan bagi Indonesia. Score yang diperoleh untuk setiap faktor kemudian disesuaikan nilainya dengan bobotnya. Dengan metode ini faktor-faktor yang mempunyai score tinggi dan bobot penting akan mendapat nilai akhir yang lebih tinggi dibandingkan dengan faktor-faktor yang mempunyai score tinggi tetapi bobot yang kurang penting. Penjumlahan "score tertimbang" akan memberikan gambaran apakah kekuatan internal Indonesia lebih tinggi atau rendah dibandingkan dengan kelemahan internalnya. Nilai yang mendekati 0,3 menunjukkan bahwa kekuatan internal Indonesia score-nya lebih tinggi dibandingkan kelemahannya, sedangkan nilai yang mendekati -0,3 menunjukkan bahwa score kelemahan yang lebih tinggi dibandingkan kekuatan.

Pendekatan yang sama dilakukan untuk memberikan penilaian terhadap faktor-faktor kesempatan dan ancaman. Dalam konteks kesempatan dan ancaman, score yang mendekati 0,3 menunjukkan bahwa kesempatan lebih tinggi nilai tertimbangnya dibandingkan ancaman, sedangkan score yang mendekati -0,3 menunjukkan bahwa nilai tertimbang kesempatan lebih rendah dari ancaman. 


\subsection{Hasil Score SWOT IE-CEPA}

Hasil simulasi diberikan pada tabel dan diagram berikut.

\begin{tabular}{cc}
\hline \hline $\begin{array}{c}\text { Score tertimbang } \\
\left(\text { Kekuatan/Kelemahan) }^{*}\right)\end{array}$ & $\begin{array}{c}\text { Score tertimbang } \\
(\text { Kesempatan /Ancaman) }\end{array}$ \\
\hline 0,1 (skala 0,1 $-0,3)$ & 0,25 (skala 0,1 -0,3) \\
(Kekuatan) & (Kesempatan) \\
\hline
\end{tabular}

Hasil score tertimbang yang dihasilkan untuk faktor internal (kekuatan dan kelemahan) sebesar 0,1, sementara untuk score tertimbang yang dihasilkan untuk faktor eksternal (kesempatan dan ancaman) adalah sebesar 0,25. Dari score yang dihasilkan, maka didapatkan hasil pada kuadran 1 yaitu kebijakan yang diambil mendukung strategi agresif pemerintah.

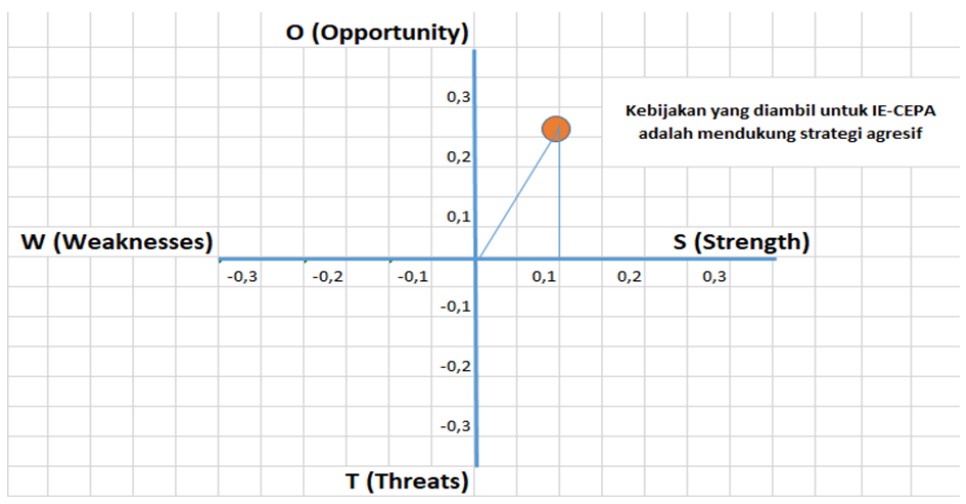

Untuk faktor strength, sebagian besar responden menganggap indikator tingkat kesesuaian dan komplementaritas ekspor Indonesia terhadap permintaan impor EFTA, merupakan faktor penting sebagai kekuatan Indonesia dalam upaya meningkatkan akses pasar ke EFTA. Untuk faktor opportunity, responden melihat indikator potensi barang yang dapat diekspor ke EFTA menjadi indikator yang penting sehingga menjadi indikator yang memiliki nilai tertimbang paling besar di antara indikator lainnya. Untuk faktor weakness, responden mengganggap pelaku usaha dan konsumen Indonesia belum mengenal banyak tentang EFTA sehingga indikator tersebut menjadi indikator kelemahan yang memiliki nilai tertinggi. Untuk faktor threat, responden menganggap indikator pelaku usaha Indonesia harus siap berkompetisi dengan pelaku usaha EFTA, terutama untuk produk sejenis merupakan ancaman yang harus diwaspadai.

Hasil SWOT ini menempati kuadran 1 dan ini merupakan posisi yang terbaik, karena posisi Indonesia berada pada daerah yang "kuat" dan "berpeluang". Pada kuadran ini, sangat memungkinkan bagi Indonesia untuk melakukan pertumbuhan yang agresif karena memiliki peluang dan kekuatan yang dibutuhkan. 
Strategi yang harus ditetapkan pada posisi ini adalah kebijakan pertumbuhan yang agresif (Growth-oriented Strategy).

\section{Kesimpulan dan Rekomendasi}

\subsection{Kesimpulan}

Hasil simulasi Cost Benefit IE CEPA menunjukkan hasil yang berkorelasi antara kenaikan output di beberapa sektor (meat product, apparel, dan textiles) yang diikuti dengan adanya peningkatan neraca perdagangan di sektor yang sejenis. Kenaikan output ini akan menyebabkan excess supply sehingga juga akan mendorong peningkatan ekspor sehingga akan mendorong terjadinya surplus neraca perdagangan. Adanya kerja sama IE-CEPA ini juga akan memberikan peningkatkan GDP Indonesia sebesar 1,8\%, sementara Swiss akan memperoleh penurunan GDP -8,3\%.

Simulasi kuantitatif analisa SWOT yang diperoleh melalui Focus Group Discussion menyimpulkan bahwa untuk perjanjian IE-CEPA posisi Indonesia mempunyai kekuatan (S) dan dihadapkan pada banyak kesempatan (O). Dengan demikian, hasil analisa ini menunjukkan bahwa Indonesia mampu menjalankan strategi agresif (Strategi SO) dengan memanfaatkan kekuatan domestik Indonesia untuk menarik manfaat sebesar-besarnya dari peluang-peluang eksternal yang ada dari amandemen perjanjian ini.

Hasil SWOT ini menempati kuadran 1 dan ini merupakan posisi yang terbaik, karena posisi Indonesia berada pada daerah yang "kuat" dan "berpeluang". Pada kuadran ini, sangat memungkinkan bagi Indonesia untuk melakukan pertumbuhan yang agresif karena memiliki peluang dan kekuatan yang dibutuhkan. Strategi yang harus ditetapkan pada posisi ini adalah kebijakan pertumbuhan yang agresif (Growth-oriented Strategy). Posisi offensive ini dapat dipertimbangkan dengan melihat hasil cost benefit terhadap peningkatan output Indonesia bagi produksi sektoral yang juga akan berpengaruh terhadap penyerapan tenaga kerja di Indonesia.

\subsection{Rekomendasi}

Berdasarkan pertimbangan-pertimbangan Cost and Benefit Analysis dan analisa SWOT di atas, maka rekomendasi dari studi ini bagi Pemerintah Indonesia adalah untuk meningkatkan perdagangan, khususnya ekspor dengan EFTA, penting bagi Indonesia agar mampu menghapus (elimination) atau mengurangi (reduction) hambatan tarif yang saat ini masih ada. Sebagai informasi, bea masuk untuk beberapa produk negara EFTA, yaitu produk hasil laut dan olahan masih sangat tinggi, dan produk laut merupakan salah satu produk andalan EFTA. Bagi pelaku usaha IE CEPA ini penting, karena dapat sebagai pintu masuk produk Indonesia ke kawasan Eropa lainnya. Ketika kerja sama perdagangan IE-CEPA diimplementasikan, maka Indonesia harus meningkatkan daya saing industri ketika penurunan dan penghapusan tarif, terutama peningkatan daya saing 
pada sektor meat product (termasuk makanan olahan), apparel, dan textile sebagai andalan Indonesia.

Berdasarkan analisis SWOT, Indonesia diharapkan segera untuk meratifikasi perjanjian ini karena faktor-faktor kekuatan lebih tinggi daripada faktor-faktor kelemahan, begitu pula faktor-faktor kesempatan lebih tinggi daripada faktorfaktor ancaman. Dengan besarnya kakuatan serta kesempatan yang dimiliki Indonesia, diharapkan agar manfaatnya dapat segera dinikmati oleh para pelaku usaha.

Keterbatasan studi ini adalah pada ruang lingkupnya yang hanya dibatasi pada sektor barang sehingga disarankan dapat dilakukan studi yang memiliki lingkup yang lebih luas yaitu mencakup jasa, investasi, IPR, dan lain sebagainya.

\section{Daftar Pustaka}

[1] Anggoro, R., \& Widyastutik, W. (2016). Non-tariff barriers and factors that influence the Indonesian cocoa export to Europe. Signifikan: Jurnal Ilmu Ekonomi, 5(1), 1-14. doi: https://doi.org/10.15408/sjie.v5i1.3131.

[2] Balassa, B. (1965). Trade liberalisation and "revealed" comparative advantage. The Manchester School, 33(2), 99-123. doi: https://doi.org/10.1111/j.14679957.1965.tb00050.x.

[3] BPS. (2019a). Statistik perdagangan luar negeri Indonesia: Ekspor 2019 Jilid II. Jakarta: Badan Pusat Statistik.

[4] BPS. (2019b). Statistik perdagangan luar negeri Indonesia: Impor 2019 Jilid II. Jakarta: Badan Pusat Statistik.

[5] Itakura, K. (2014). Impact of liberalization and improved connectivity and facilitation in ASEAN. Journal of Asian Economics, 35, 2-11. doi: https://doi.org/10.1016/j.asieco.2014.09.002.

[6] Kotabe, M. M., \& Helsen, K. (2001). Global marketing management (2nd edition). John Wiley \& Sons.

[7] Meier, G. (1995). Leading issues in economic development (6th edition). Oxford University Press.

[8] Rao, D. (2011). Past achievements and future challenges of the European Free Trade Association - twenty years of trade relations and beyond (1991-2011...). MILE 11 Thesis Universität Bern. World Trade Institute. Retrieved from https://www.wti.org/media/filer_public/8c/30/ 8c303fcb-1a1d-443f-a83b-1f87f5099a16/masters_thesis_darius_rao.pdf.

[9] Salamah, L. (2017). Analisa Strengths, Weaknesses, Opprotunities, and Threats (SWOT): Peluang dan tantangan Association of Southeast Asian Nations (ASEAN) dalam mewujudkan integrasi Asia Tenggara. Masyarakat, Kebudayaan dan Politik, 30(3), 300-309. doi: http:/ /dx.doi.org/10.20473/mkp.V30I32017.300-309.

[10] Stevens, C., Irfan, M., Massa, I., \& Kennan, J. (2015). The impact of Free Trade Agreements between developed and developing countries on economic development in developing countries (Rapid evidence assessment, July 2015). Overseas Development Institute. Retrieved from https://www.gov.uk/dfid-research-outputs/ the-impact-of-free-trade-agreements-between-developed-and-developing-countrieson-economic-development-in-developing-countries-a-rapid-evidence-assessment. 
[11] Trade Map. (2019). Trade statistics for international business development. Retrieved from www.trademap.org. 